\title{
Awareness of complications of diabetes mellitus and its associated factors among type 2 diabetic patients at Addis Zemen District Hospital, northwest Ethiopia
}

\author{
Yitayeh Belsti ${ }^{*}$ (D), Yonas Akalu' ${ }^{1}$, Haileab Fekadu² and Yaregal Animut ${ }^{2}$
}

\begin{abstract}
Objectives: Awareness about complications is important to reduce diabetes related morbidity and mortality. This study aimed to assess awareness of diabetes complications and associated factors among type 2 diabetic patients. Institution based cross sectional study was conducted from April to June, 2019, using simple random sampling technique, and interviewer administered questionnaires.

Results: The mean age was $41 \pm 1.46$ years and $56 \%$ were females. Awareness regarding diabetic complications was $48.5 \%$ with $95 \% \mathrm{Cl}(43.3,52.7 \%)$. Male sex (AOR: $4.67,95 \% \mathrm{Cl}(2.53,8.61))$, age of $31-45$ years (AOR: $7.30,95 \% \mathrm{Cl}$ (3.10, 17.17)), 46-70 years old (AOR: $15.02,95 \% \mathrm{Cl}(6.11,36.92))$, read and write (AOR: $3.79,95 \% \mathrm{Cl}(1.78,8.06))$, primary school (AOR: $9.58,95 \% \mathrm{Cl}(3.26,28.18)$ ), high school and above (AOR: 7.46, 95\% Cl (3.02, 18.44)), NGO employee (AOR: 7.24, $95 \% \mathrm{Cl}(2.68,19.53))$, having a family history of DM (AOR: $5.55,95 \% \mathrm{Cl}(2.53,12.20))$; income of 1001-1500 (AOR: 3.22, 95\% Cl (1.28, 8.10)), 1501-2500 (AOR: 11.73, 95\% Cl (4.32, 31.81)) and > 2500 Ethiopian birr (AOR: $7.18,95 \% \mathrm{Cl}(1.70$, $30.28)) \geq 2500$ ETB (AOR: $7.18,95 \% \mathrm{Cl}(1.70,30.28)$ ) were significantly associated with good awareness. To improve patient's awareness on DM complications providing health education for type 2 diabetic patients is crucial.
\end{abstract}

Keywords: Diabetes complication, Type 2 diabetics, Ethiopia

\section{Introduction}

Diabetes mellitus (DM), a group of metabolic disorders characterized by high blood glucose levels over a prolonged period, is increasing rapidly in both developed and developing countries [1]. Unless appropriate intervention is taken, it is expected that there will be at least 350 million people in the world with type 2 diabetes by the year 2030 [2]. Type 2 diabetes will be the predominant public health problem in Africa which is expected to be 28 million by 2030 [3] and 41.6 million in 2045 [4]. According to the International Diabetes Federation (IDF) report, there were 2, 652,129 cases of diabetes in Ethiopia in 2017 making it the first among the top five countries of

\footnotetext{
*Correspondence: yitayehbelsti@gmail.com

${ }^{1}$ Department of Physiology, College of Medicine and Health Sciences, University of Gondar, Gondar, Ethiopia

Full list of author information is available at the end of the article
}

Africa for a number of people with diabetes with the age of 18-99 years [4].

Most consequences of diabetes result from its complications which include: retinopathy, diabetic foot, renal complications, stroke, heart complications, neuropathy, hypertension, and sexual dysfunction [5]. Prevalence of diabetes and its complications are increasing alarmingly which brought a heavy burden to patients and health system [5]. A systematic review and meta-analysis in the Republic of Ireland 1998-2015 show that the prevalence of diabetic complications is increasing [6]. Studies done in Ethiopia showed that prevalence of visual disturbance, neuropathy, nephropathy and diabetic foot ulcer were $33.8 \%, 29.5 \%, 15.7 \%$ and $13.6 \%$ respectively $[7,8]$. More than $(59.7 \%)$ half of diabetic patients were found to have been affected by one or more of the diabetic complications [9]. 
Most DM complications are highly preventable through increasing awareness [10, 11]. Creating awareness about the disease, treatment, and its complications is the first step in managing disease and furthermore to facilitate prevention and control activities [11-13]. In addition, adherence to treatment requires awareness about nature and complication of the disease [12, 14-16]. However, Lack of awareness on diabetes complications contributes to high rates of complications [17].

In Ireland awareness rates of ischemic heart disease and stroke among diabetic population was 89.2 and $82.8 \%$, respectively [18], while that of Pakistan was 50\% [13]. According to the IDF report most Ghanaians had lack of awareness about diabetic complications [16]. In a study in Pakistan has shown that living in urban was associated with better knowledge [19], whereas in India, being male, family history of diabetes mellitus, higher education status and executive jobs were predictor of better awareness [12]. Health education and counseling at diabetic clinic during their follow up, and repeated media exposures provide key messages on diabetes management and prevention of its complications [12]. There is no published data regarding the awareness of diabetic complications and its predictors in Ethiopia. That is why this study was conducted to assess awareness of diabetes complication and its associated factor among type 2 diabetes patients at Addis Zemen District Hospital, northwest Ethiopia.

\section{Main text}

Patients and methods Study design, area, and period

Institution-based cross-sectional study design was employed from April 02, 2019 to June 02, 2019 at Addis Zemen District Hospital, northwest Ethiopia.

\section{Source and study population}

All type 2 diabetic patients of Addis Zemen Hospital were the source population and all type 2 diabetic patients who came to diabetic clinic during the 3 months of data collection period were the study population.

\section{Sample size determination and sampling technique}

The sample size was calculated by using a single population proportion formula with assumptions; $\mathrm{p}=50 \%$ (as there was no previous study in Ethiopia), 95\% level of confidence and $5 \%$ margin of error. Then sample size became 384 . After adding 5\% oversampling, the minimum calculated sample was 404. Computer generated simple random sampling technique was used to select the study participants.

\section{Inclusion and exclusion criteria}

All type 2 diabetic patients who were on medication for more than 1 year and $\geq 18$ years old were included. All type 2 diabetes mellitus patients who were seriously ill and health professionals were excluded.

\section{Variables of the study}

Dependent variable Awareness.

Independent variables Age, sex, residence, marital status, occupation, educational status, income, duration since diagnosis as diabetic, family history DM.

\section{Operational definitions}

DM complications presence of one or more of complications on DM patients such as retinopathy, diabetic foot, renal complications, stroke, heart complications, teeth decay, neuropathy, hypertension, and sexual dysfunction [20].

Rural residence settling in country side outside of big cities or towns in Ethiopia are referred as rural residents [21].

Family history of DM having at least one-first-degree relative with diabetes [22].

\section{Data collection instrument and procedure}

Pretested structured interviewer-administered questionnaire, which is adapted from different literatures, was used to collect the data [15, 23-26]. The questioner contains 28 diabetes complications related awareness items. The possible correct answers for assessing awareness of diabetes complications were 28. The awareness of the patient was calculated by summating the correct answers and calculating the mean value as 15 with minimum and maximum correct answers of 5 and 25 respectively. The participant who mentioned less than mean [15] correct answers grouped as have no awareness. The participant who mentioned $\geq 15$ correct answers grouped as having awareness. The questionnaire was prepared in English first and translated to local language and then, re translated back to English by another person to check its consistency and wording.

\section{Data quality management/control}

Training was given for data collectors and supervisors about the aim of the study, data collection procedure and ethical issues. Validity was checked by doing pretest on 60 type 2 DM patients at University of Gondar Hospital (out of the study area). Modification of the tool was made based on the pre-test result. The Cronbach's alpha scale for awareness questions was done for all questions and it was greater than 0.7 , which is 
acceptable. Close supervision was made during data collection. Data clean up and crosschecking was also done before analysis.

\section{Data analysis procedure}

The data were checked for completeness and entered to Epi Info version 7 and were exported to SPSS Version 20 for analysis. Descriptive statistics such as frequencies and percentage were used. A binary logistic regression was used to identify predictors of awareness on DM complications. On bivariable analysis, variables with a p-value $<0.2$ were entered to multivariable logistic regression model. $\mathrm{p} \leq 0.05$ were used to declare statistically significant variables in the final model.

\section{Results}

\section{Socio-demographic characteristics of respondents}

The study was conducted on 402 study participants. Fifty-six percent patients were female. The mean age was $41(\mathrm{SD} \pm 1.46)$ years. Concerning age, $150(37.3 \%)$ of the respondents were aged 46 to 70 years. Majority $91(22.6 \%)$ had an educational level of high school and above. Over one-third (33.8\%) of the respondents had a monthly income of below 500 Ethiopian birr. One hundred and eighteen (29.4\%) study participants had a family history of diabetic mellitus (Table 1).

\section{Awareness about complications of DM}

In this study, 195 (48.5\%) of the diabetic patients had awareness of DM complications with 95\% CI (43.3, 52.7). Over two-third (62.9\%) of patients were informed about diabetes complications from health professionals. Most of the study participants 372 (92.5\%) had knowledge of dietary modification to prevent diabetes complications. Three hundred sixty-seven (91.3\%) knew about complication related risk factor of alcohol and cigarette smoking. Diabetic foot 297 (73.9\%) was the most known complication of DM followed by eye complications 292 (72.6\%), and heart complications 254 (63.2\%) (Table 2).

\section{Factors associated with awareness of diabetes mellitus complications among DM patients}

All independent variables were tested for crude association with awareness by binary logistic regression. However, after adjusting for potential confounders in the multivariable analysis, being; male (AOR: 4.67, 95\% CI $(2.53,8.61)$ ), in the age of $31-45$ years (AOR: $7.30,95 \%$ CI $(3.10,17.17)$ ), 46-70 years old (AOR: 15.02, 95\% CI $(6.11,36.92))$, educational level of read and write (AOR: 3.79, 95\% CI $(1.78,8.06))$, primary school [1-8] (AOR:
Table 1 Socio demographic characteristics of type 2 adult DM patients at Addis Zemen District Hospital, Gondar, Ethiopia, $(\mathrm{N}=402)$

\begin{tabular}{|c|c|c|}
\hline Variables & Frequency & Percent (\%) \\
\hline \multicolumn{3}{|l|}{ Sex } \\
\hline Male & 177 & 44.0 \\
\hline Female & 225 & 56.0 \\
\hline \multicolumn{3}{|l|}{ Age } \\
\hline $18-30$ & 134 & 33.3 \\
\hline $31-45$ & 118 & 29.4 \\
\hline $46-70$ & 150 & 37.3 \\
\hline \multicolumn{3}{|l|}{ Level of education } \\
\hline Cannot write and read & 110 & 27.4 \\
\hline Read and write & 124 & 30.8 \\
\hline Primary & 77 & 19.2 \\
\hline High school and above & 91 & 22.6 \\
\hline \multicolumn{3}{|l|}{ Marital status } \\
\hline Married & 202 & 50.2 \\
\hline Divorced & 37 & 9.2 \\
\hline Widowed & 49 & 12.2 \\
\hline Single & 114 & 28.4 \\
\hline \multicolumn{3}{|l|}{ Occupation } \\
\hline Farmer & 85 & 21.1 \\
\hline Government worker & 46 & 11.4 \\
\hline Merchant & 104 & 25.9 \\
\hline Housewife & 77 & 19.2 \\
\hline NGO worker & 90 & 22.4 \\
\hline \multicolumn{3}{|l|}{ Religion } \\
\hline Orthodox & 304 & 75.6 \\
\hline Muslim & 68 & 16.9 \\
\hline Protestant & 30 & 7.5 \\
\hline \multicolumn{3}{|l|}{ Ethnicity } \\
\hline Amhara & 348 & 86.6 \\
\hline Kimant & 35 & 8.7 \\
\hline Tigrie & 19 & 4.7 \\
\hline \multicolumn{3}{|l|}{ Residence } \\
\hline Rural & 159 & 39.6 \\
\hline Urban & 243 & 60.4 \\
\hline \multicolumn{3}{|l|}{ Duration of DM } \\
\hline$(1-5)$ & 270 & 67.2 \\
\hline$(6-10)$ & 93 & 23.1 \\
\hline$>10$ & 39 & 9.7 \\
\hline \multicolumn{3}{|c|}{ Type of medication they use } \\
\hline Oral & 133 & 33.1 \\
\hline Injectable & 218 & 54.2 \\
\hline Both & 51 & 12.7 \\
\hline \multicolumn{3}{|l|}{ Family history of DM } \\
\hline Yes & 118 & 29.4 \\
\hline No & 284 & 70.6 \\
\hline
\end{tabular}


Table 1 (continued)

\begin{tabular}{lcc}
\hline Variables & Frequency & Percent (\%) \\
\hline Income & & \\
$<500$ & 156 & 38.8 \\
$500-1500$ & 68 & 16.9 \\
$1501-2500$ & 86 & 21.4 \\
$>2500$ & 92 & 22.9 \\
Have you been informed about complications of diabetes? & \\
Yes & 301 & 74.9 \\
No & 101 & 25.1 \\
Where did you get information about DM complications? & \\
Health worker & 253 & 62.9 \\
Friend/parent & 27 & 6.7 \\
TV/radio & 19 & 4.7 \\
Other & 2 & 0.5 \\
\hline
\end{tabular}

$D M$ diabetes mellitus, $N$ number, $T V$ television

a Reading books

9.58, 95\% CI $(3.26,28.18)$ ), high school and above (AOR: 7.46, 95\% CI $(3.02,18.44)$ ), being NGO employee (AOR: $7.24,95 \% \mathrm{CI}(2.68,19.53))$, having a family history of DM (AOR: $5.55,95 \%$ CI $(2.53,12.20)$ ); income of 1001-1500 (AOR: 3.22, 95\% CI $(1.28,8.10)$ ), 1501-2500 (AOR: 11.73, 95\% CI $(4.32,31.81)$ ) and $>2500$ Ethiopian birr (AOR: $7.18,95 \%$ CI $(1.70,30.28))$ were significantly $(\mathrm{p}<0.05)$ associated with a good knowledge (Table 3 ).

\section{Discussions}

This study has provided data about the awareness of complications of diabetes mellitus among diabetic patients at Addis Zemen Hospital, northwest Ethiopia. Comprehensive assessment of the awareness of 402 patients on DM complications showed that less than half of participants had awareness. This finding is consistent with the study conducted in Ghana (40\%) [25], Bangladesh (42\%) [26], and in Pakistan [24]. On the contrary, it is not in line with a study conducted in Saudi Arabia on awareness of diabetic complications which reported that $80 \%$ of participants were aware about complications of diabetes. The reason for the difference may be because of a difference in socioeconomic conditions, cultural beliefs and habits, as studies showed that differences in such variables had an impact on the pattern of awareness on diabetic complications [27]. In the current study, age, sex, educational level, occupation, and family history of DM were significantly associated with awareness of DM complications. This finding, except for age, is congruent with the study done in India [12]. In the current study those who were male were 4.6 times more likely to have awareness than females. Consistently, a study in Pakistan showed that
Table 2 Awareness on DM complications among type 2 DM patients at Addis Zemen Hospital, Ethiopia

\begin{tabular}{|c|c|c|c|}
\hline Variables & Categories & Number & Percent \\
\hline \multirow{4}{*}{$\begin{array}{l}\text { What is the normal fast- } \\
\text { ing blood sugar level? }\end{array}$} & $<70 \mathrm{mg} / \mathrm{dl}$ & 38 & 9.5 \\
\hline & $70-110 \mathrm{mg} / \mathrm{dl}$ & 77 & 19.2 \\
\hline & $>126 \mathrm{mg} / \mathrm{dl}$ & 6 & 1.5 \\
\hline & Don't know & 281 & 69.9 \\
\hline \multirow{6}{*}{$\begin{array}{l}\text { What are the most } \\
\text { common symptoms of } \\
\text { high blood sugar? }\end{array}$} & Increased thirst & 309 & 76.9 \\
\hline & Frequent urination & 295 & 73.4 \\
\hline & Blurring of vision & 130 & 32.3 \\
\hline & Weakness & 185 & 46 \\
\hline & Dry mouth & 102 & 25.4 \\
\hline & Confusion & 30 & 7.5 \\
\hline \multirow{5}{*}{$\begin{array}{l}\text { What are the most com- } \\
\text { mon symptoms of low } \\
\text { blood sugar? }\end{array}$} & Palpitation & 157 & 39.1 \\
\hline & Tremor & 220 & 54.7 \\
\hline & Sweating & 238 & 59.2 \\
\hline & Blurring of vision & 107 & 26.6 \\
\hline & Decreased coordination & 62 & 15.4 \\
\hline \multirow{9}{*}{$\begin{array}{l}\text { Which of the following } \\
\text { complications can hap- } \\
\text { pen when diabetes is } \\
\text { not well controlled? }\end{array}$} & Diabetic foot & 297 & 73.9 \\
\hline & Eye complications & 292 & 72.6 \\
\hline & Heart complications & 254 & 63.2 \\
\hline & Neuropathy & 217 & 54.0 \\
\hline & Renal complications & 216 & 53.7 \\
\hline & Stroke & 157 & 39.1 \\
\hline & Teeth decay & 130 & 32.3 \\
\hline & Hypertension & 142 & 35.3 \\
\hline & Sexual dysfunction & 102 & 25.4 \\
\hline \multirow{2}{*}{$\begin{array}{l}\text { Can dietary modifica- } \\
\text { tion prevent diabetic } \\
\text { complication? }\end{array}$} & Yes & 372 & 92.5 \\
\hline & No & 30 & 7.5 \\
\hline \multirow{2}{*}{$\begin{array}{l}\text { Can Stop smoking/ } \\
\text { and alcohol stopping } \\
\text { prevent diabetic com- } \\
\text { plication? }\end{array}$} & Yes & 367 & 91.3 \\
\hline & No & 35 & 8.7 \\
\hline \multirow{2}{*}{$\begin{array}{l}\text { Is physical work or exer- } \\
\text { cise help to prevent } \\
\text { diabetes complication? }\end{array}$} & Yes & 343 & 85.3 \\
\hline & No & 59 & 14.7 \\
\hline \multirow{4}{*}{$\begin{array}{l}\text { If you are beginning } \\
\text { to have a low blood } \\
\text { glucose reaction, you } \\
\text { should? }\end{array}$} & 1. Exercise & 16 & 4.0 \\
\hline & 2. Lie down and rest & 85 & 21.1 \\
\hline & 3. Drink some juice & 193 & 48.0 \\
\hline & $\begin{array}{l}\text { 4. Take rapid-acting } \\
\text { insulin }\end{array}$ & 108 & 26.9 \\
\hline \multirow{4}{*}{$\begin{array}{l}\text { What you should do } \\
\text { when your blood sugar } \\
\text { is raised? }\end{array}$} & 1. Dietary modification & 87 & 21.6 \\
\hline & 2. Physical exercise & 10 & 2.5 \\
\hline & 3. Lowering stress & 79 & 19.7 \\
\hline & 4. Take insulin & 226 & 56.2 \\
\hline
\end{tabular}

DM diabetes mellitus

being male was predictor of better awareness [24]. The justification for this finding might be due to cultural influence which allows females to spend their time in house, but males spent most of their time outside the home that gave them more chance to acquire more information and 
Table 3 Factors associated with awareness of DM complications among DM patients at Addis Zemen Hospital, Ethiopia

\begin{tabular}{|c|c|c|c|c|}
\hline \multirow[t]{2}{*}{ Variable } & \multicolumn{2}{|c|}{ Knowledge status $(n=402)$} & \multicolumn{2}{|l|}{ OR $(95 \% \mathrm{Cl})$} \\
\hline & Poor N (\%) & Good N (\%) & COR & AOR \\
\hline \multicolumn{5}{|l|}{ Sex } \\
\hline Male & $64(36.2)$ & $113(63.8)$ & $3.08(2.04,4.64)$ & $4.67(2.53,8.61)^{* * *}$ \\
\hline Female & $143(63.6)$ & $82(36.4)$ & 1 & 1 \\
\hline \multicolumn{5}{|l|}{ Age } \\
\hline $18-30$ & $100(74.6)$ & $34(25.4)$ & 1 & 1 \\
\hline $31-45$ & $59(50.0)$ & $59(50.0)$ & $2.94(1.73,5.00)$ & $7.30(3.10,17.17)^{* * *}$ \\
\hline $46-70$ & $48(32.0)$ & $102(68.0)$ & $6.25(3.72,10.49)$ & $15.02(6.11,36.92)^{* * * *}$ \\
\hline \multicolumn{5}{|l|}{ Level of education } \\
\hline Cannot write and & $80(74.1)$ & $28(45.5)$ & 1 & 1 \\
\hline Read and write & $75(49.0)$ & $78(51.0)$ & $2.97(1.74,5.07)$ & $3.793(1.78,8.06)^{* *}$ \\
\hline $1-8$ & $20(40.0)$ & $30(60.0)$ & $4.29(2.11,8.73)$ & $9.59(3.26,28.18)^{* * *}$ \\
\hline High school & $32(35.2)$ & $59(59)$ & $5.27(2.86,9.68)$ & $7.46(3.02,18.44)^{* * *}$ \\
\hline \multicolumn{5}{|l|}{ Occupation } \\
\hline Farmer & $55(64.7)$ & $30(35.3)$ & 1 & 1 \\
\hline Government worker & $15(32.6)$ & $31(67.4)$ & $3.79(1.77,8.10)$ & $0.96(0.31,2.95)$ \\
\hline Merchant & $47(45.2)$ & $57(54.8)$ & $2.22(1.23,4.01)$ & $0.72(0.29,1.81)$ \\
\hline House wife & $43(55.8)$ & $34(44.2)$ & $1.45(0.78,2.73)$ & $2.93(1.13,7.56)$ \\
\hline NGO worker & $47(52.2)$ & $43(47.8)$ & $1.68(0.91,3.08)$ & $7.24(2.68,19.53)^{* * *}$ \\
\hline \multicolumn{5}{|l|}{ Residence } \\
\hline Rural & $99(62.3)$ & $60(37.7)$ & 1 & 1 \\
\hline Urban & $108(44.4)$ & $135(55.6)$ & $2.06(1.37,3.10)$ & $1.76(0.13,3.11)$ \\
\hline \multicolumn{5}{|l|}{ Duration of DM } \\
\hline$<5$ & $152(56.3)$ & $118(43.7)$ & 1 & 1 \\
\hline $5-10$ & $41(44.1)$ & $52(55.9)$ & $1.63(1.05,2.63)$ & $0.89(0.36,2.22)$ \\
\hline$>10$ & $14(35.9)$ & $25(64.1)$ & $2.30(1.15,4.62)$ & $1.25(0.47,3.29)$ \\
\hline \multicolumn{5}{|l|}{ Family history of DM } \\
\hline Yes & $19(16.1)$ & 99 (83.9) & $10.20(5.89,17.67)$ & $5.55(2.53,12.20)^{* * *}$ \\
\hline No & $188(66.2)$ & $96(33.8)$ & 1 & 1 \\
\hline \multicolumn{5}{|l|}{ Income } \\
\hline$<500$ & $93(68.4)$ & $43(31.6)$ & 1 & 1 \\
\hline $501-1000$ & $44(64.7)$ & $24(35.3)$ & $1.18(0.64,2.18)$ & $1.85(0.75,4.57)$ \\
\hline $1001-1500$ & $42(48.8)$ & $44(51.2)$ & $2.27(1.30,3.95)$ & $3.22(1.28,8.10)^{*}$ \\
\hline $1501-2500$ & $21(25.6)$ & $61(74.4)$ & $6.28(3.40,11.60)$ & $11.73(4.32,31.81)^{* * *}$ \\
\hline$>2500$ & $7(23.3)$ & $23(76.7)$ & $7.11(2.83,17.83)$ & $7.18(1.72,30.28)^{* *}$ \\
\hline
\end{tabular}

COR crude odds ratio, $A O R$ adjusted odds ratio, $C I$ confidence interval, $D M$ diabetes mellitus, $N$ number

${ }^{*} \mathrm{p}$-value $<0.05,{ }^{* *} \mathrm{p}$-value $<0.01,{ }^{* * *} \mathrm{p}$-value $<0.001,1=$ references

to attend different meetings and conferences. Age was also significantly associated with awareness of DM complications which is similar with the study done in Bangladesh [26]. Those 31-45 years old were 7.3 more likely to have awareness than those with age 15-30 years old. As age increases, they get more counseling and health education during their follow-up at the diabetic clinic and from formal and non-formal education. A higher level of education was a significant predictor of better awareness, this finding coincides with other studies [12, 24]. Those with educational level of read and write, 1-8 and, high school and above were 3.7, 9.5 and 7.4 times more aware of DM complications, respectively than those who cannot read and write. As individuals learn more, the chance of gaining information about DM complications from different sources will increase. In addition, those individuals with a high level of education can read different medical books. Another interesting finding of this study was the association between occupation and patient knowledge of diabetic complications. NGO employees were 7 times 
more likely to have awareness about diabetic complications than those who were farmers. These results agree with findings of Obirikorang et al. [24]. This is because NGO employees are mostly linked to different institution especially health institutions which create them a favorable condition to gain information about complication of DM. This study also found a significant association between income and awareness on diabetic Complications. Those patients with an income of greater than 2500 were aware of DM complications than those with income of less than $<500$. This finding is supported by other study [24]. It is clear that as income increases, individuals can access or buy any electronic media like TV, which is one means of gaining information. Another important finding of this study was patients with a family history of DM were five times more likely to have awareness on DM complications than the counterparts. This finding is consistent with the study done India [12]. This is because, they learn from their family experience. Most of diabetic patients have no awareness on diabetic complications. Age, sex, educational level, occupation, and family history of DM were significant predictors of awareness of DM complications. Health education on DM complications for type 2 diabetes patients by health professionals and through mass media should be promoted.

\section{Limitations of the study}

During assessment of knowledge of patients on DM chronic complications, even though the interviewers carried out it carefully, respondents may have replied socially acceptable responses which may cause an overestimation of awareness of study participants.

\section{Abbreviations}

DM: diabetic mellitus; NGO: non-governmental organization; AOR: adjusted odds ratio; Cl: confidence interval; COR: crude odds ratio; SPSS: statistical package for social sciences.

\section{Acknowledgements}

We would like to thank the University of Gondar for its support. The data collectors and the study participants are duly acknowledged for kindly given us the information.

\section{Authors' contributions}

YB designs the study, performed data analysis and drafted the manuscript. YA involved with designing the study, data analysis, and reviewed the manuscript. HF take part with data analysis, designing the study and reviewing the manuscript. YA participated with data analysis, designing the study and reviewed the manuscript. All authors read and approved the final manuscript.

\section{Funding}

Not applicable.

\section{Availability of data and materials}

The data will be available upon request from the corresponding author upon request.
Ethics approval and consent to participate

Ethical approval for the study was obtained from the Institute of Public Health College of Medicine and Health Sciences, University of Gondar. Written informed consent was obtained from all study participants and confidentiality was kept. All the study subjects had answered voluntarily and confidently the administered pre-tested questionnaires.

\section{Consent for publication}

Not applicable.

\section{Competing interests}

The authors declare that they have no competing interests.

\section{Author details}

${ }^{1}$ Department of Physiology, College of Medicine and Health Sciences, University of Gondar, Gondar, Ethiopia. ${ }^{2}$ Department of Epidemiology and Biostatistics, Institute of Public Health, College of Medicine and Health Sciences, University of Gondar, Gondar, Ethiopia.

Received: 27 July 2019 Accepted: 11 September 2019

Published online: 18 September 2019

\section{References}

1. World Health Organisation. Global report on diabetes. Glob Rep Diabetes. 2016;88.

2. Guariguata L, Whiting DR, Hambleton I, Beagley J, Linnenkamp U, Shaw JE. Global estimates of diabetes prevalence for 2013 and projections for 2035. Diabetes Res Clin Prac. 2014;103(2):137-49.

3. Van Dieren S, Beulens JWJ, Van Der Schouw YT, Grobbee DE, Neal B. The global burden of diabetes and its complications: an emerging pandemic. Eur J Cardiovasc Prev Rehabil. 2010;17(Suppl 1):s3-8.

4. International Diabetes Federation. IDF diabetes atlas. 8 ed. 2017. p. 1-150.

5. Mao W, Yip CW, Chen W. Complications of diabetes in China: health system and economic implications. BMC Public Health. 2019;19(1):269. https //doi.org/10.1186/s12889-019-6569-8.

6. Tracey ML, Gilmartin M, O’Neill K, Fitzgerald AP, McHugh SM, Buckley CM, et al. Epidemiology of diabetes and complications among adults in the Republic of Ireland 1998-2015: a systematic review and meta-analysis. BMC Public Health. 2016;16(1):132. https://doi.org/10.1186/s1288 9-016-2818-2.

7. Worku D, Hamza L, Woldemichael K. Patterns of diabetic complications at Jimma university specialized hospital, southwest Ethiopia. Ethiop J Health Sci. 2010;20(1):33-9.

8. Bekele BB. The prevalence of macro and microvascular complications of DM among patients in Ethiopia 1990-2017: systematic review. Diabetes Metab Syndr. 2019;13(1):672-7. https://doi.org/10.1016/j.dsx.2018.11.046.

9. Abejew AA, Belay AZ, Kerie MW. Diabetic complications among adult diabetic patients of a tertiary hospital in northeast Ethiopia. Adv Public Health. 2015:2015:1-7.

10. Aldawish SN, Alsomali AH, Jalawi A, Alkhars AA. Knowledge and awareness of diabetic foot complications in diabetic patients. Egypt J Hosp Med. 2018;72(10):5371-4.

11. Somannavar S, Lanthorn H, Deepa M, Pradeepa R, Rema M, Mohan V. Increased awareness about diabetes and its complications in a whole city: effectiveness of the "prevention, awareness, counselling and evaluation" [PACE] Diabetes Project [PACE-6] [PACE-6]. J Assoc Physicians India. 2008;56(7):497-502.

12. Murugesan N, Snehalatha C, Shobhana R, Roglic G, Ramachandran A. Awareness about diabetes and its complications in the general and diabetic population in a city in southern India. Diabetes Res Clin Pract. 2007;77(3):433-7. https://doi.org/10.1016/j.diabres.2007.01.004.

13. Agrawaal KK. Patients' awareness about the complications of diabetes mellitus and its co relation with the glycemic status. JNMA J Nepal Med Assoc. 2015;53(200):284-7. https://doi.org/10.31729/jnma.2747.

14. Menezes S, Mohammed Bava M. A study on awareness of diabetic complications among type 2 diabetes patients. IOSR J Dent Med Sci. 2015;14(11):2279-861.

15. Fatani EM, Gari LN, Alharbi AH. Awareness of diabetic complications, perceived knowledge, compliance to medications and control of diabetes 
among diabetic population of Makkah city, Kingdome Saudi Arabia: cross-sectional study. Egypt J Hosp Med. 2018;70(7):1190-5. https://doi. org/10.12816/0044548.

16. Aschner P, Beck-Nielsen H, Bennett P, Boulton A, Colagiuri R, Colagiuri $\mathrm{S}$, et al. Global guideline for type 2 diabetes. Diabetes Res Clin Pract. 2014;104(1):1-52.

17. Bos M, Agyemang C. Prevalence and complications of diabetes mellitus in Northern Africa, a systematic review. BMC Public Health. 2013;13:387.

18. O'Sullivan EP, Bhargava A, O'Callaghan M, Buckley U, De Faoite T, Moynihan K, et al. Awareness of diabetes complications in an Irish population. Ir J Med Sci. 2009;178(4):401-6. https://doi.org/10.1007/s11845-009-0301-0

19. Sabri AA, Qayyum MA, Saigol NU, Zafar K, Aslam F. Comparing knowledge of diabetes mellitus among rural and urban diabetics. Mcgill J Med. 2007;10(2):87-9.

20. WWorld Health Organization. Definition, diagnosis and classification of diabetes mellitus and its complications: report of a WHO consultation. Part 1, Diagnosis and classification of diabetes mellitus. Geneva: World health organization; 1999

21. Dorosh P, Schmidt E. The rural-urban transformation in Ethiopia. International Food Policy Research Institute (IFPRI). ESSP Work Pap. 2010. http:// www.ifpri.org/publication/rural-urban-transformation-ethiopia. Accessed Jun 2010.

22. Zhang J, Yang Z, Xiao J, Xing X, Lu J, Weng J, et al. Association between family history risk categories and prevalence of diabetes in Chinese population. PLoS ONE. 2015;10(2):1-13.
23. Tang YH, Pang SM, Chan MF, Yeung GS, Yeung VT. Health literacy, complication awareness, and diabetic control in patients with type 2 diabetes mellitus. J Adv Nurs. 2008;62(1):74-83. https://doi.org/10.111 1/j.1365-2648.2007.04526.x.

24. Ullah F, Afridi AK, Rahim F, Ashfaq M, Khan S, Shabbier G, et al. Knowledge of diabetic complications in patients with diabetes mellitus. J Ayub Med Coll Abbottabad. 2015;27(2):360-3.

25. Obirikorang Y, Obirikorang C, Anto EO, Acheampong E, Batu EN, Stella $A D$, et al. Knowledge of complications of diabetes mellitus among patients visiting the diabetes clinic at Sampa Government Hospital, Ghana: a descriptive study. BMC Public Health. 2016;16(1):1-8. https://doi. org/10.1186/s12889-016-3311-7.

26. Rahaman KS, Majdzadeh R, Holakouie Naieni K, Raza O. Knowledge, attitude and practices (KAP) regarding chronic complications of diabetes among patients with type 2 diabetes in Dhaka. Int J Endocrinol Metab. 2017;15(3):e12555.

27. Hawthorne K, Tomlinson S. Pakistani moslems with type 2 diabetes mellitus: effect of sex, literacy skills, known diabetic. Diabet Med. 1999;16(7):591-7.

\section{Publisher's Note}

Springer Nature remains neutral with regard to jurisdictional claims in published maps and institutional affiliations.
Ready to submit your research? Choose BMC and benefit from:

- fast, convenient online submission

- thorough peer review by experienced researchers in your field

- rapid publication on acceptance

- support for research data, including large and complex data types

- gold Open Access which fosters wider collaboration and increased citations

- maximum visibility for your research: over $100 \mathrm{M}$ website views per year

At BMC, research is always in progress.

Learn more biomedcentral.com/submissions 